Please do not remove this page

RMIT

UNIVERSITY

\title{
A hybrid embedded cohesive element method for predicting matrix cracking in composites
}

Joosten, Mathew; Dingle, Matthew; Mouritz, Adrian; Afaghi Khatibi, Akbar; Agius, Steven; Wang, Chun https://researchrepository.rmit.edu.au/esploro/outputs/9921862585601341/filesAndLinks?institution=61 RMIT_INST\&index=null

Joosten, M., Dingle, M., Mouritz, A., Afaghi Khatibi, A., Agius, S., \& Wang, C. (2016). A hybrid embedded cohesive element method for predicting matrix cracking in composites. Composite Structures, 136, 554-565. https://doi.org/10.1016/j.compstruct.2015.10.030

Document Version: Accepted Manuscript

Published Version: https://doi.org/10.1016/j.compstruct.2015.10.030

Repository homepage: https://researchrepository.rmit.edu.au (C) 2015 Elsevier Ltd.

Downloaded On 2023/04/26 22:39:11 +1000 
Thank you for downloading this document from the RMIT Research Repository.

The RMIT Research Repository is an open access database showcasing the research outputs of RMIT University researchers.

RMIT Research Repository http://researchbank.rmit.edu.au/

\section{Citation:}

Joosten, M, Dingle, M, Mouritz, A, Afaghi Khatibi, A, Agius, S and Wang, C 2016, 'A hybrid embedded cohesive element method for predicting matrix cracking in composites', Composite Structures, vol. 136, pp. 554-565.

See this record in the RMIT Research Repository at:

https://researchbank.rmit.edu.au/view/rmit:34677

Version: Accepted Manuscript

Copyright Statement: (C) 2015 Elsevier Ltd.

Creative Commons Attribution-NonCommercial-NoDerivatives 4.0 International License.

Link to Published Version:

http://dx.doi.org/10.1016/j.compstruct.2015.10.030 


\section{Accepted Manuscript}

A Hybrid Embedded Cohesive Element Method for Predicting Matrix Cracking in Composites

Mathew W. Joosten, Matthew Dingle, Adrian Mouritz, Akbar A. Khatibi, Steven Agius, Chun H. Wang

PII: S0263-8223(15)00962-9

DOI: http://dx.doi.org/10.1016/j.compstruct.2015.10.030

Reference: COST 6939

To appear in:

Composite Structures

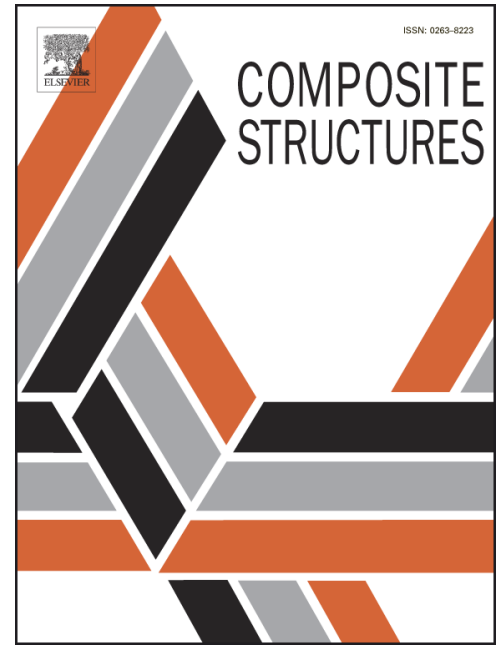

\section{To appear in:}

Please cite this article as: Joosten, M.W., Dingle, M., Mouritz, A., Khatibi, A.A., Agius, S., Wang, C.H., A Hybrid Embedded Cohesive Element Method for Predicting Matrix Cracking in Composites, Composite Structures (2015), doi: http://dx.doi.org/10.1016/j.compstruct.2015.10.030

This is a PDF file of an unedited manuscript that has been accepted for publication. As a service to our customers we are providing this early version of the manuscript. The manuscript will undergo copyediting, typesetting, and review of the resulting proof before it is published in its final form. Please note that during the production process errors may be discovered which could affect the content, and all legal disclaimers that apply to the journal pertain. 


\section{A Hybrid Embedded Cohesive Element Method for Predicting Matrix Cracking in Composites}

Mathew W Joosten ${ }^{1}$, Matthew Dingle ${ }^{2}$, Adrian Mouritz ${ }^{1}$, Akbar A Khatibi ${ }^{1}$, Steven Agius $^{3}$, Chun H Wang ${ }^{1 *}$

${ }^{1}$ Sir Lawrence Wackett Aerospace Research Centre, School of Aerospace, Mechanical, and Manufacturing Engineering, RMIT University, Melbourne, GPO Box 2476, Melbourne VIC 3001, Australia.

${ }^{2}$ Carbon Revolution Pty. Ltd, Geelong Technology Precinct, Waurn Ponds, VIC, 3216, Australia.

${ }^{3}$ School of Engineering, Faculty of Science and Engineering and Built Environment, Deakin University, Waurn Ponds, VIC, 3216, Australia.

Abstract: The complex architecture of many fibre-reinforced composites makes the generation of finite element meshes a labour-intensive process. The embedded element method, which allows the matrix and fibre reinforcement to be meshed separately, offers a computationally efficient approach to reduce the time and cost of meshing. In this paper we present a new approach of introducing cohesive elements into the matrix domain to enable the prediction of matrix cracking using the embedded element method. To validate this approach, experiments were carried out using a modified Double Cantilever Beam with ply drops, with the results being compared with model predictions. Crack deflection was observed at the ply drop region, due to the differences in stiffness, strength and toughness at the bi-material interface. The new modelling technique yields accurate predictions of the failure process in composites, including fracture loads and crack deflection path.

(Keywords: Composite Materials, Delamination, Cohesive Elements, Fibre bridging, Embedded Element Method)

\footnotetext{
* Corresponding author: chun.wang@rmit.edu.au
} 


\section{Introduction}

Safety-critical fibre-reinforced polymer composite structures are designed so that no damage growth, such as matrix cracking from the resin-rich region at the end of a dropped ply, will occur at the design limit loads [1, 2]. Furthermore, any matrix cracks emanating from manufacturing flaws or impact damage by foreign objects cannot grow to exceed critical size limits during service. Therefore matrix-dominated cracking is a major concern for the design and operation of safety-critical fibre reinforced composite structures. Many low cost out-of-autoclave manufacturing techniques, such as closed moulding processes (e.g. Resin Transfer Moulding (RTM)), vacuum-assisted resin infusion, and pultrusion, are capable of producing high-quality composite components with properties comparable to those produced by autoclave using prepregs. However, these processes can result in more complex resin-rich regions and reinforcement architectures than laminates made of prepregs. Computational analyses of these composite structures require the time intensive and laborious development of a very fine finite element mesh to accurately represent the geometrical features of resin regions and reinforcement fabrics or fibre tows. In automotive and maritime applications, the fibre composite components can be even more geometrically complex and thicker than the aerospace structures that are typically thin-gauge structures reinforced with stringers or honeycomb cores. Determination of the critical loads that may cause matrix cracking in thick composite structures requires accurate analysis of the 3D stress state through the thickness of the component. Currently accurate prediction of the 3D stress state typically involves modelling the structure with a fine mesh of three-dimensional (3D) elements. Generating this contiguous 3D 
solid mesh for a composite structure that has complex geometry and resin-rich regions pertinent to ply-drops and inserted fibre tows require significant effort, making this conventional approach inefficient.

The embedded element technique [3-7] offers an alternative approach, allowing the polymer matrix and fibre reinforcement to be meshed separately. Specifically, the entire volume of the composite component is meshed using hexahedral or tetrahedral elements to form the host domain. The embedded domain comprises all the reinforcement layers. Each layer is initially meshed as a 2D surface, which is extruded to form the 3D solid mesh. These two sets of meshes are fused together by tying the nodal displacements of the embedded domain with the interpolated displacements of the host domain. The resulting model accurately represents the stiffness of the composite structure. The embedded element technique has shown its potential as a computationally efficient modelling technique in a broad range of applications from the analysis of reinforced concrete [4], reinforced rubber tyres [3] and fibre reinforced composite structures [5-10].

Yang and Cox $[9,10]$ used the embedded element technique (which is also called the "Binary Model") to predict the strength of un-notched and notched (open hole) composite specimens, and demonstrated that this method offered a significant increase in computational efficiency over a homogenised finite element (FE) model. The binary model, in its original formulation for application to textile composites, represents the contribution of the axial stiffness of fiber tows by 1D "tow elements" 
embedded in a 3D "effective medium" that accounts for all other stiffness contributions. Yang and Cox demonstrated the importance of gauge-averaging methods used in conjunction with the binary model formulation [9] and also generalised the formulation by using strings of $1 \mathrm{D}$ elements, rather than a single string of elements, to represent a single tow [9]. When averaged over a gauge length comparable to the tow width, the predicted local strain variations became independent of the number of strings, $N$, for $N=4$ or 16 . Yang and Cox remarked that in the limit $N \rightarrow \infty$, the binary model becomes equivalent to a representation in which the fibre tows appear as continuous 3D bodies embedded in an effective medium, as in the formulation of Fish [11], but with more limited degrees of freedom available to describe local elasticity. The 3D formulation originated by Fish [11, 12] was further developed by Hallett and colleagues under the name "domain superposition technique" [8] and more recently by Tabatabaei et al $[7,13]$.

The embedded element technique has been used primarily to determine the stiffness of and failure onset in composite materials [7-10, 13-15]. However, modelling the progression of damage using the embedded element approach has not been attempted to the authors' knowledge. Two key challenges are (1) the appropriate method of combining the stress fields of the host and embedded domains to enable strength prediction and (2) the introduction of damage progression criteria to simulate growth of in-service damage or manufacturing defects. 
The principal objective of this study is to advance the embedded element technique by introducing a damage progression modelling technique to predict delamination cracking in composite structures containing resin-rich regions (e.g. near ply-drops). Introducing cohesive elements requires prior knowledge of the crack path and this process is relatively straightforward in monolithic laminates fabricated with continuous plies, as the cracking is generally along ply interfaces. Resin-rich regions due to plydrops and fibre tow, which are more commonly encountered in low-cost manufacturing techniques such as RTM, can cause crack deflection when the matrix crack tip reaches the resin-rich region. Modelling of crack deflection often requires prior knowledge of the crack propagation path and the use of cohesive elements or cohesive surface technique. Although the issue of pre-seeding the crack path could be avoided using mesh insensitive techniques [16-18], the cohesive modelling approach is adopted in this study because of its relative maturity for implementation by the composites industry. In addition, a cohesive model can be used as a benchmark to evaluate other modelling approaches in terms of accuracy and computational costs. The ability to model interlaminar failure within the embedded element framework represents a major advancement towards the development of an efficient modelling technique for complex structures. This new approach is validated by predicting the evolution of matrix cracking in a modified Double Cantilever Beam (DCB) sample of a composite material that contains two discontinuous plies. 


\section{Hybrid Embedded Cohesive Element Method}

\subsection{Existing Embedded Element Approach}

To facilitate the description of the damage progression model, it is advantageous to briefly summarise the essential features of the embedded element approach. When modelling fibre-reinforced composites the host domain encloses the volume of a structure or component as shown in Figure 1(b). The fibre reinforcement domain is located within the matrix and may fill all or part of the matrix domain as shown in Figure $1(\mathrm{c})$. The two domains are coupled or fused together with the displacement of the embedded domain tied to the interpolated displacements of the host domain, thereby, combining the stiffness properties of these two constituents $[5-10,14]$. It should be noted that rotational degrees of freedom are generally not coupled.

\subsubsection{Stiffness of domains}

In resin-rich regions without fibre reinforcement, the host domain must assume the matrix properties. In regions where the embedded domain coincides with the host domain, referring to Figure $1(c)$, then the stiffness of the composite structure is equal to the sum of the stiffness contributions of the matrix and reinforcement. Hence the necessary stiffness matrix of the embedded domain, $[E]^{R}$, is the difference between those pertinent to the composite and the matrix [8]:

$$
[E]^{R}=[E]^{C}-[E]^{M}
$$


where the superscripts $R, M$, and $C$ denote quantities pertinent to the reinforcement (embedded domain), matrix (host), and composite, respectively. The threedimensional stiffness matrices required for this relationship can be obtained from [19].

\subsubsection{Recovering the stresses in composite}

The stresses in the resin-rich regions are simply those in the host domain. In regions where the host and the embedded domains coincide, two coincident stress fields pertinent to the contributions of the matrix and reinforcement exist. A simple summation of the stress fields is sufficient when the embedded domain and the host domain have identical mesh. In this case the sum of the reinforcement and matrix stress fields $\sigma$ are equivalent to that of the composite:

$$
[\sigma]^{C}=[E]^{C}\{\varepsilon\}=\left([E]^{R}+[E]^{M}\right)\{\varepsilon\}=[\sigma]^{R}+[\sigma]^{M}
$$

Tabatabaei et al. [7] have shown that the embedded element approach can provide a reasonable prediction of the stress field at the interface between the two domains provided the mesh is sufficiently fine.

In many cases where the meshes are not coincidental, Yang and Cox proposed the use of averaged stresses (or strains) over a characteristic distance, termed the gauge length $[9,10]$. One issue with the differing mesh densities is that singularities may arise at the interface of the two domains due to the significant differences in elastic stiffness. However, the mechanisms of failure that are most commonly seen in polymer reinforced textile composites are not generally associated with a point value 
of stress, due to intrinsic fracture toughness. Instead, they are governed by some measure of the strain or stress averaged over a spatial gauge length or volume [10].

\subsubsection{Mesh creation procedure}

Rapid mesh generation is the major advantage of the embedded element technique. By first meshing the host and embedded domains independently and subsequently fusing them together, the two sets of elements do not need to be coincidental and no special treatment of the boundaries between the two domains is required. The geometry of the host domain is simply the enclosed volume of the component or structure being modelled. This geometry is readily available from a CAD model or X-ray CT scan of a manufactured component. With this input, the host domain mesh can be rapidly generated by meshing the entire volume with tetrahedral elements, which are capable of discretising complex geometries with ease. Isotropic material properties are assigned to the host domain and therefore a material orientation is not required.

The geometry of the embedded domain can be extracted from a CAD model or X-ray CT scans as ply surfaces. The ply surfaces are typically used to "lay up" a composite component in a CAD model, to create ply cutting templates, and are therefore digitally available from the design drawings. The mesh of the embedded domain is generated by surface meshing the plies and then extruding the resulting $2 \mathrm{D}$ mesh by the ply thickness to create a 3D mesh of the plies. The orthotropic (or anisotropic) material properties and ply orientation are assigned to the 3D elements. The material orientation can be applied to the $3 D$ mesh from information contained in the CAD model or X-ray images. 
Once the host and embedded domains are meshed and material properties applied, the two domains can then be fused together by coupling the displacements of the embedded domain to the interpolated displacement of the host domain. This can be accomplished automatically in Abaqus using the "*embedded element" feature with the matrix region as the host domain and the reinforcement region as the embedded domain. The finite element model is solved once loads and boundary conditions are applied to the host domain.

\subsection{Coupling Embedded Element and Cohesive Element Methods}

To enable the prediction of damage progression using the embedded element approach, cohesive elements are introduced into the host domain as shown in the bottom left image of Figure 1(d). In addition, cohesive surfaces are inserted between plies or fibre tows (bottom two images in Figure $1(\mathrm{e})$ ) in the embedded domain to capture the toughening effects of fibre bridging. This new approach is denoted as "hybrid embedded cohesive element method". The cohesive elements or surfaces are assigned a traction-separation response that relates the displacement jump of the element to a traction based on a continuum damage mechanics response [20] that reduces the secant material stiffness, $K$, to a damage variable, $d$. A schematic representation of a cohesive traction response is shown in Figure 2. Domain-specific traction laws are introduced and identification of the required material properties are described in Section 4. 
Prior to the onset of damage the cohesive elements have a linear-elastic response and the damage function is zero. Once the onset of damage occurs, $d>0$, a reduction is stress and corresponds to a non-zero damage function. The secant stiffness, (1-d)K, will decrease until the damage function, $d$, reaches unity and the cohesive elements can carry no further load. The unidirectional composite structures investigated in the current study exhibit large scale fibre bridging that acts as a crack shielding mechanism. The influence of large scale fibre bridging can be included using a user defined traction response described in detail in Section 4.1.1

Within the framework of the hybrid embedded cohesive element technique there are three possible fracture paths as shown in Figure 3. The properties assigned to cohesive surfaces (or elements) for each of these paths require a unique set of material properties for the three cases:

1. Cracking within the host domain (the resin-rich region).

2. Cracking within the embedded region (reinforcement domain coincident with host domain).

3. Cracking along the interface between the embedded domain and host domain.

The relevant cohesive strength and fracture energy for these three cases need to be determined separately and are described in the following. 


\subsubsection{Cracking within a resin-rich region (host domain)}

Modelling failure within resin-rich regions (represented by the host domain) can be achieved by inserting cohesive elements in the host domain along the predicted crack path. The stiffness, $E$, and strength, $S$, of these elements are the same as the properties of the matrix material. The Mode I and Mode II fracture toughness, $G_{I c}$ and $G_{\text {IIc }}$ respectively, can be used to represent the behaviour of the interface under pure mode loading. The effect of mode mixity is introduced using an appropriate interaction criterion such as a Power law, B-K law [21], or a bilinear relationship [22].

\subsubsection{Cracking in the reinforced region}

Simulating delamination in reinforced regions is achieved by inserting cohesive elements in the matrix domain. Since the two adjacent fibre reinforcement plies do not share nodes, i.e., they are free to separate if the host domain elements become damaged, interlaminar failure is modelled using cohesive elements within the host domain only. The cohesive elements are assigned with the material properties of the composite, including the through-thickness modulus, $E_{33}$, through-thickness shear moduli, $G_{13}, G_{23}$ and the associated failure strengths, $\sigma_{33}, \tau_{13}$ and $\tau_{23}$. The mode I and mode II fracture energies, $G_{l c}, G_{\| l c}$ can be obtained from standard tests with mode mixity treated using a power law [23]. This approach negates the need to "gauge" average the stresses as discussed previously. If delamination occurs between two unidirectional plies, as in the current study, the influence of crack fibre bridging is accounted for by employing cohesive surfaces between adjacent reinforcement elements. Details are provided in Section 4. 


\subsubsection{Cracking along the interface with the reinforced region and resin-rich region}

In the current study it is assumed that cracking at the interface between the reinforced regions and resin-rich regions occurs entirely within the matrix phase and does not cause fibre rupture in the composite plies. Therefore in the current study the properties assigned to cohesive elements at the interface of the two domains are those pertinent to matrix failure.

\section{Experimental Details}

To validate the proposed modelling technique, further details are given in Section 4, experimental tests were carried out using carbon fibre-epoxy composites based on the geometry of the DCB specimen as described in ASTM D5528 [20]. The composite lay-up was modified at the mid-plane of the laminate by introducing two discontinuous plies. The discontinuous plies created a resin-rich region along the primary delamination path. The purpose of this feature is to introduce a resin-rich region (bi-material interface) into the composite and examine crack propagation and deflection across this low-stiffness region, which is a common damage mode for composite structures.

\subsection{Specimen manufacture}

Specimens were manufactured from eighteen plies of unidirectional carbon fibreepoxy (VTM264) prepreg with a lay-up of $\left[0_{8}, 0^{*}\right]_{s}$, where * represents a ply that does not span the full length of the laminate; namely, a discontinuous ply. A polytetrafluoroethylene (PTFE) film was inserted at the mid-plane of the laminate to 
introduce a pre-crack in the specimen. The termination location of the discontinuous ply relative was located $20 \mathrm{~mm}$ from the end of the PTFE insert. The two plies were manually laid, resulting in a small offset approximately equal to a ply thickness of 0.21 $\mathrm{mm}$ between the ends of the two dropped plies. The laminate was cured in an autoclave at $120^{\circ} \mathrm{C}$ and 90 psi for 1 hour as per the prepreg manufacturer's specifications. The cured thickness of the panel was $3.85 \mathrm{~mm}$ in the full thickness region (18 plies) and $3.45 \mathrm{~mm}$ in the 16-ply region. A schematic of the ply terminations is shown in Figure 5.

\subsection{Experimental procedure}

DCB tests were conducted on specimens with the geometry shown in Figure 3 using an Instron 4466 tensile machine operated in displacement control at a rate of 2.0 $\mathrm{mm} / \mathrm{min}$, in accordance with the ASTM standard [20]. The load and displacement were recorded at a rate of $4 \mathrm{~Hz}$. The position of the crack was monitored using a travelling microscope. Periodically the test was paused after the crack had advanced approximately $2.0 \mathrm{~mm}$. While the displacement was held constant the crack length was measured, and then loading was resumed. Once the crack tip was observed to advance an additional $2.0 \mathrm{~mm}$ the test was paused and this process was repeated until the crack advanced approximately $40 \mathrm{~mm}$ from its initial position or $20 \mathrm{~mm}$ past the resin-rich region. Six identical DCB samples were tested under the same conditions to assess any variability in the fracture process and mode. 


\subsection{Results}

A typical load-displacement curve for the ply-drop specimens is shown in Figure 6 . The square markers represent when the test was paused to record the position of the crack. Five distinct phases were observed, as denoted by the letters in Figure 6 . Phase I corresponded to elastic loading of the sample where no crack propagation was observed. Phase II was a region of stable crack growth that continued until the crack tip reached the ply termination. Once the crack tip reached the ply termination, denoted phase III, stable crack growth ceased and the load increased. Since the toughness of the epoxy resin is comparable to the initial interlaminar fracture toughness of the carbon-epoxy composite, the increase in load shown in Figure 5 was unexpected. This increase occurred when the crack deflected away from the centreline of the DCB sample. Upon reaching the ply above the dropped ply, the crack followed the composite-resin interphase, with the load showing a sudden drop denoted as Phase IV. During this event the crack advanced $12 \mathrm{~mm}$, after which stable crack growth, Phase V, was re-established.

An optical micrograph of the crack path as it progressed past the ply-termination is shown in Figure 7. The numerals on the bottom of the figure correspond to the failure phases shown in Figure 6. Deflection of the crack as it entered the resin-rich region was observed. The crack propagated slowly through the resin-rich region until it reached the next adjacent continuous ply after which the crack resumed to grow along the ply/resin interface, referred to hereafter as the ply-resin interphase region. Once 
the crack progressed past the resin-rich region it re-entered the composite region and stable crack growth continued.

The fracture surfaces of the samples, particularly near the ply drop region, were examined using a scanning electron microscope (SEM). A SEM image of the fracture surface and a schematic representation of the observed fracture path are shown in Figure 8 . The crack propagated between plies until reaching the end of a ply termination, after which the crack deflected and propagated within the resin-rich region.

The increased load required to propagate a crack through the resin-rich region was unexpected. The toughness of the bulk epoxy is comparable to the initiation toughness of the composite, as such, it was expected that the crack propagation would be confined to the mid-plane of the laminate. During testing crack deflection was observed and can be attributed to the mismatch in elastic stiffness at the bi-material interface and the difference in strength between the composite and bulk epoxy. The strength of the bulk epoxy is $80 \mathrm{MPa}$ compared with $40 \mathrm{MPa}$ in the transverse and though-thickness of the composite laminate. In the composite the presence of the carbon fibres introduce stress concentrations in the matrix, thereby, reducing the out of plane strength. The mismatch in stiffness and different strengths on either side of the bi-material interface both contribute to the toughening mechanism as the crack propagates through this region. 


\section{Predicting the evolution of matrix cracking with the}

\section{embedded element technique}

Following the description of the hybridised embedded cohesive element technique in Section 2.2 the identification of appropriate cohesive properties used to define the initiation and propagation of matrix cracking is described.

\subsection{Identification of model parameters}

The stiffness matrix of the embedded domain can be calculated using Equation 2 provided the stiffness matrices of the composite and matrix are known. The mechanical properties of the composite and the matrix material are shown in Table 1 and Table 2 respectively. The stiffness properties for the undirectional carbon-epoxy ply were obtained from [24] for a fibre volume fraction of $56 \%$. The stiffness and strength of the epoxy matrix were obtained from the manufacturer. Using Equation 2 the elastic modulii and Poisson's ratios for the embedded domain were calculated so that the combined stiffness of the host and embedded domains is equivalent to the cured laminate or composite stiffness, as described in Section 2.1, and they do not represent the properties of the dry reinforcement. These values, as listed in Table 3, were then assigned to the embedded domain. 


\subsubsection{Cohesive material properties}

To model the behaviour of the matrix (and interphase region), the stiffness and strength of the resin provided by the manufacturer were used. The fracture energy of the resin, $G_{l c}$, was measured by independent tests at RMIT. A summary of the cohesive properties used in the numerical simulations are shown in Table 4. A quadratic interaction between the normal and shear opening modes, $\alpha=2.0$, was assumed.

Significant fibre bridging occured between the $0^{\circ}$ plies during delamination growth, as is commonly observed when performing mode I DCB tests on specimens fabricated from carbon-epoxy prepreg [5]. To account for the contribution of fibre bridging in the cohesive model, the method by Sørensen et al. [25] was employed to calculate the mode I bridging tractions. The approach involves measuring the crack tip opening at the initial crack tip position $\left(a=a_{0}\right), \delta_{a 0}$. The J-integral was evaluated along a path containing the crack face in the bridged zone and the crack tip, and this relationship can be expressed as:

$$
G_{I}=\int_{0}^{\delta_{a 0}} \sigma(\delta) d \delta+G_{i}
$$

where $G_{i}$ denotes the intrinsic fracture toughness of the matrix material. The mode I fracture toughness is calculated from the measured load-displacement data using:

$$
G_{I}=\frac{P^{2}}{E I b}\left(\frac{3 E I \delta}{2 P}\right)^{\frac{2}{3}}
$$

where $E$ denotes the elastic modulus, I the moment of inertia of one DCB arm, $P$ the applied force, and $\delta$ the opening displacement at the load application point. From 
these measurements a relationship between mode I fracture toughness and crack opening displacement was obtained, which can be fitted with a cubic polynomial:

$$
G_{I}\left(\delta_{a 0}\right)=A_{0}+A_{1} \delta_{a 0}+A_{2} \delta_{a 0}^{2}+A_{3} \delta_{a 0}^{3}
$$

For the present material system, the coefficients $A_{0}, A_{1}, A_{2}$ and $A_{4}$ are equal to $0.3555,0.7087,-0.7620$, and 0.2721 , respectively. Figure 9 presents the experimental data and the fitted polynomial. The bridging stress can now be obtained by taking the derivative of the toughness with respect to opening displacement at the crack tip $\delta_{a 0}$ :

$$
\sigma\left(\delta_{a 0}\right)=\frac{d G_{I}}{d \delta_{a 0}}=A_{1}+2 A_{2} \delta_{a 0}+3 A_{3} \delta_{a 0}^{2}
$$

This function describes the cohesive damage via a stiffness reduction given by:

$$
E=\left(1-D\left(\delta_{a 0}\right)\right) E_{0}
$$

where $E$ is the effective modulus, $E_{0}$ is the undamaged modulus, and $D\left(\delta_{a 0}\right)$ is the damage function governing the bridging response can be obtained using:

$$
D\left(\delta_{a 0}\right)=1-\left(\frac{L}{E_{33}}\right)\left(\frac{\sigma\left(\delta_{a 0}\right)}{\delta_{a 0}}\right)
$$

where $L$ is the length of the cohesive element normal to the crack growth.

The definition of a cohesive failure model requires the definition of two distinct mechanisms, namely brittle matrix failure and large scale fibre bridging. After damage initiates it is assumed that the traction response is linear. The assumption of a linear reduction in stress is a reasonable assumption and also used by other researchers [25]. The area under the stress displacement curve equal to the initiation toughness of the composite which is the current case is $0.35 \mathrm{~kJ} / \mathrm{mm}^{2}$. With a mode I initiation stress of 
$40 \mathrm{MPa}$, and an un-damaged interfacial stiffness of 7.5 GPa the gradient of the traction response for brittle matrix failure can be defined. After exceeding a critical displacement threshold the interfacial damage transitions from a traditional cohesive zone to a fibre bridging mode. The critical displacement threshold is the intercept between the fibre bridging response (Equation 3) and the linear stress reduction representing brittle matrix failure. For the current case the critical displacement is $0.0172 \mathrm{~mm}$ and can be observed in Figure 10. Once the critical displacement is exceeded the cohesive stress is obtained using Equation 3. By combining the linear cohesive response and the influence of large scale fibre bridging the resultant composite damage function was obtained. A graph of the mode I crack bridging stress as a function of the opening displacement from a single cohesive element is shown in Figure 10. Note that the fibre bridging response is presented in the inset graph (top right). Cohesive elements were inserted in the matrix domain along the mid-plane of the laminate, as such, these elements experienced Mode I loading with little mixed mode loading. The square markers in Figure 10 (top right) are the experimentally measured rate of change of fracture toughness with respect to the opening displacement at the crack tip $\delta_{a 0}$. The line in Figure 10 (top right) represents the derivative of Equation 5 with respect to the opening displacement at the crack tip $\delta_{a 0}$. The composite traction law was separated into domain specific laws following the procedure described by Airoldi and Davila [26]. One law represents interlaminar matrix failure and another to represents the fibre bridging mechanism. A user-defined damage function was assigned to the 3D cohesive elements (COH3D8) in the reinforcement domain using a tabular form to represent the interlaminar behaviour of 
the composite. The tabular damage function was calculated using Equation 6 and 8. A bi-linear traction law was assigned to the cohesive elements within the matrix domain.

\subsection{Crack path discretisation}

When using cohesive elements the crack path must be discretised a priori. For the plydrop DCB specimens investigated in the current study, crack deflection was observed as the crack progressed past the ply-termination as shown in Figure 13. The ply terminations induce mode mixity at the crack tip. Static stress analysis was used to determine the crack deflection angle, $\theta$, as shown in Figure 13. The local crack tip stresses were extracted at a distance of $0.0021 \mathrm{~mm}$ from the crack tip for angles ranging from $-90^{\circ}$ to $90^{\circ}$, and these values were used to calculate the dimensionless angular functions for the stress intensity factors in mode I and mode II:

$$
\begin{gathered}
f_{1}(\theta)=\frac{\sigma_{\theta \theta}(r, \theta) \sqrt{2 \pi r}}{\sqrt{E_{m} G\left(1-v_{m}^{2}\right)}} \\
f_{2}(\theta)=\frac{\tau_{\theta \theta}(r, \theta) \sqrt{2 \pi r}}{\sqrt{E_{m} G\left(1-v_{m}^{2}\right)}}
\end{gathered}
$$

where $\sigma_{\theta \theta}(r, \theta)$ and $\tau_{\theta \theta}(r, \theta)$ are the tangential and radial shear stresses at a distance $r$ inclined at angle $\vartheta$ from the crack tip. The parameters $E_{m}$ and $v_{m}$ are the elastic modulus and Poisson's ratio of the matrix, respectively $\left(E_{m}=3.8 \mathrm{GPa}\right.$ and $\left.v_{m}=0.33\right)$. The total energy release rate, G, was calculated using the VCCT. The results of $f_{1}(\theta)$ and $f_{2}(\theta)$ are plotted as a function of $\vartheta$ in Figure 14. It is clear that the maximum tangential stress occurs at $\vartheta=32^{\circ}$, indicating a possible angle of crack deflection. 
However, another potential deflection path is the bi-material interface along angle $\vartheta=$ $90^{\circ}$, where the shear stress reaches a maximum. Experimental observations along the free edge (see Figure 7) and fracture surfaces (see Figure 8 ) of the samples revealed that crack deflection occurred between $80-90^{\circ}$. The likely reason for this mode of deflection is that the bi-material interface might have lower tensile strength than that of the matrix, due to the stress concentration created by the terminating plies. To assess the influence of deflection angles on the fracture strength, two models were used to predict the evolution of interlaminar failure with the crack path deflecting at either $32^{\circ}$ or $90^{\circ}$.

\subsection{Meshing strategy}

The embedded element model requires two distinct domains to be discretised; namely, the host and embedded domains. The FE representation of the reinforced regions, with the mesh edges hidden, is shown in Flgure 13. It should be noted that each ply was meshed independently and did not share common nodes with the elements in the adjacent ply layer(s). When using the embedded element technique the resin-rich regions are naturally included without needing to explicitly partition the model into separate regions. The inclusion of resin-rich regions, without explicitly requiring any additional user effort, is a major advantage of the embedded element technique, particularly when analysing large complex composite structures.

One key issue with modelling interlaminar failure with cohesive elements is the inherent mesh dependency. The size of a cohesive element is dependent on the 
stiffness, strength and toughness property values assigned to the elements. To address this problem, Turon et al. [27] suggested that a minimum of three elements in the cohesive zone are required to accurately represent the fracture energy release. The length of the cohesive zone, $I_{c z}$ is defined as the distance from the crack tip to the point when the maximum cohesive traction is attained. The length of the cohesive zone can be determined using [27]:

$$
l_{c z}=B E_{33} \frac{G_{I C}}{\left(S_{33}\right)^{2}}
$$

where and $B$ is a parameter that depends on the cohesive zone theory. The value of $B$ can vary between 0.22 and 1.0 [20], and in the current work it was conservatively set to unity. Using Equation (11) the cohesive zone lengths, $I_{c z}$, for the composite and the epoxy matrix (in the absence of any fibre reinforcement) are calculated as $1.4 \mathrm{~mm}$ and $0.21 \mathrm{~mm}$, respectively. Based on the restriction in element size three modelling approaches were investigated in the current study, namely, a coarse FE model with a $90^{\circ}$ crack deflection angle and two finely meshed models with crack deflection angles of $32^{\circ}$ and $90^{\circ}$. In the coarsely meshed model the matrix cracking was constrained to the bi-material interface, hence a very fine FE mesh is not essential. In this case a single cohesive element was used to represent the interface between the ply termination and the resin-rich region. Including a cohesive element at the ply termination greatly simplifies the meshing process and the reduced mesh size; the smaller number of degrees of freedom would significantly reduce the computational time of the simulation. The global mesh size of the coarse model was equal to a ply thickness, $0.21 \mathrm{~mm}$. 
For the fine mesh models a maximum element size of $0.052 \mathrm{~mm}$ was adopted for modelling cohesive failure in the interphase regions. The cohesive elements within the interphase region were meshed with a maximum edge length of $0.05 \mathrm{~mm}$. The size of the cohesive elements within the composite region were $0.05 \mathrm{~mm}$ at the ply termination after which the element transitioned from 0.05 to $0.22 \mathrm{~mm}$ over a distance of $0.43 \mathrm{~mm}$. The thickness of the cohesive elements was constant throughout the model and equal to $0.01 \mathrm{~mm}$. The geometry and detail of the matrix domain meshes for the two crack deflection angles $90^{\circ}$ and $32^{\circ}$ are shown in Figure 13 . The boundary of the reinforcement domain has been superimposed onto the matrix domain meshes as a red shaded area. The cohesive elements, shaded yellow, formed a continuous path, thereby allowing the crack to propagate in a similar manner to that observed experimentally.

Cohesive elements that were bounded on both sides by fibre reinforcement elements were assigned composite fracture properties incorporating the effect of fibre bridging, as discussed in Section 4.2. For cohesive elements that were adjacent to a matrix element, their properties were assigned as the matrix properties shown in Table 4. The cohesive elements in the coarse model were $0.21 \mathrm{~mm}$ in length and therefore equal to the cohesive zone length. Since three elements are typically required to represent the cohesive zone [27], the initiation stress for cohesive elements in the interphase region was reduced in accordance with the recommendations of Turon et al. [27], using Equation 9 with 3 elements in the cohesive zone. Therefore, the cohesive strength for 
these elements was reduced from $80 \mathrm{MPa}$ to $46 \mathrm{MPa}$ and all other parameters remained unchanged.

For computational efficiency a thin $0.05 \mathrm{~mm}$ slice of the specimen was modelled under the plane strain condition, as the stiffness of the resin-rich region was much less than the transverse stiffness of the composite plies. Airoldi and Davila [26] have shown that modelling a thin slice of a full DCB sample under plane stress or plane strain conditions can provide a similar response as a full width model. The plane strain condition ensures that the resin-rich region did not deform out-of-plane as the crack propagated through this region. Rigid bodies were assigned to the ends of the laminate and the model was loaded using a prescribed displacement boundary condition as per the experimental setup. The reaction forces and vertical displacement of the master rigid body nodes were written to a history file to facilitate comparison with experimental test data.

\section{Comparison with Experimental results}

The predicted load-displacement responses of the three models are compared with experimental test data in Figure 14. Crack initiation was predicted at the same load level as observed in the experiments. Following crack initiation, the load level was approximately constant as fibre bridging took effect. At approximately $5.6 \mathrm{~mm}$ of applied displacement (point A) the crack tip had reached the end of the ply termination and crack growth was arrested and the load was observed to increase. As the crack propagated through the resin-rich region differences between the three 
models became more evident. The coarse mesh approach gave conservative prediction compared to the fine $90^{\circ}$ model. The finely meshed $32^{\circ}$ model produced the largest under-prediction as the crack propagated through this region.

Deformed FE meshes for the reinforcement domain and the host domain, as the crack propagated through the resin-rich region are shown in Figure 15 and Figure 16. It should be noted that the fully failed elements are defined as elements that have zero stiffness (damage $=1.0$ ). A red contour represents elements that have completely failed, whereas blue contour indicates undamaged elements. As the crack entered the resin-rich region adjacent to the ply termination deflection was enforced by the spatial orientation of the cohesive elements with respect to the mid-plane. Stable crack growth was observed as the crack slowly grew into the resin-rich region. As the crack reached the next continuous ply another deflection occurred (see Figure 15 and Figure 16) after which rapid unstable crack growth was predicted. The fibre bridging mechanism was represented by cohesive elements inserted between two unidirectional $0^{\circ}$ plies and tractions due to fibre bridging can only occur once interlaminar matrix failure has occurred in the host domain. If adjacent fibre reinforcement plies are of different orientations, for example a $45^{\circ}$ ply adjacent to a $90^{\circ}$ ply, fibre bridging would not occur and therefore insertion of cohesive elements would not be required. It should be noted that the no cohesive elements are needed along the surface of reinforcement domains adjacent to resin rich region where no fibre bridging will occur. 
A crack deflection angle of $90^{\circ}$ allowed the model to more closely predict the loaddisplacement behaviour observed during experimental testing. This is consistent with the experimentally observed crack deflection angle at the specimen edges $\left(80^{\circ}\right)$. In the experiments the crack path was not smooth and uniform as represented in the FE models; rather it follows a more tortuous path. It is therefore likely that the crack deflection across the width of the specimen was very close to the ply end or the bimaterial interface.

The predicted crack growth is compared with experimental observations in Figure 17. The position of the crack was extracted from the numerical models using a custom python script. Consistent with the experimental observation, the numerical modelling also predicted five distinct phases; namely, elastic loading, stable crack growth, crack deflection, rapid crack advancement followed by stable crack growth. All models were capable of predicting the observed failure phases and the evolution of delamination. However, the fine FE model with a crack deflection angle of $90^{\circ}$ more closely matched the crack growth path observed experimentally and a crack deflection angle of $90^{\circ}$ is consistent with the fracture surface observed from SEM images. 


\section{Discussion}

Previous research $[7,9,10,14]$ has focussed on the use of the embedded element technique for static stiffness and strength calculation. The work reported herein extends the embedded element approach to predicting delamination growth in fibre reinforced composite structures. By employing a coupled cohesive element/embedded element model, accurate predictions were achieved for the crack path and fracture loads of matrix crack growing across a resin-rich region. In the current study interlaminar failure was represented by cohesive elements inserted along the delamination path in the matrix domain (effective medium). The properties assigned to the cohesive elements were dependent on the presence of reinforcement elements: if reinforcement elements were adjacent to a cohesive element, composite properties were assigned and in the absence of reinforcement elements the properties of the bulk epoxy were assigned. Simulating crack growth using cohesive elements requires the crack path to be specified a priori and cohesive elements (or surfaces) must be inserted in the matrix domain along the delamination path. Discretisation of the crack path may partially negate a key benefit of using the embedded element approach, which is reducing the time taken to mesh a complex model. However, the crack path must also be discretised when employing a traditional solid modelling approach. With the embedded element technique the matrix and reinforcement domains are coincident in the regions representing the plies. Therefore, there are more degrees of freedom compared with a traditional solid model. The increased degrees of freedom make the embedded element approach more computationally expensive than an equivalent solid model. However, for a complex structure the pre-processing cost, 
particularly the generation of a contiguous FE mesh is significantly reduced when comparing the embedded element approach to traditional 3D solid modelling methods.

The modelling approach proposed in this paper constrains the crack to grow either between plies or along the bi-material interface. This assumption allowed the structure to be discretised with a relatively coarse mesh. By reducing the cohesive material properties [27] to suit the element size, the coarse model provides similar accuracy as a finely meshed model and reduced the computational expense by a factor of 8 . It is therefore recommended that the coarse modelling approach be used to simulate failure in more complex structures with a large number of degrees of freedom.

The current study presents progress towards a computationally efficient method to predict interlaminar failure in thick complex composite structures using the embedded element technique. To increase the attractiveness of the method an alternative to cohesive elements is required to avoid the need to pre-seed the crack path with cohesive elements (or surfaces). There are two analysis approaches that could be adapted to represent failure without discretisation of the crack path; namely, Continuum Damage Mechanics (CDM) [17] and the eXtended Finite Element Method (XFEM) [18]. One issue that needs to be addressed with these approaches is how fibre bridging should be taken into account. For matrix cracks propagating parallel to the fibre direction, strong fibre bridging can occur. For example, fibre bridging can occur between two adjacent $0^{\circ}$ plies or within a ply following an intralaminar matrix crack. 
This extrinsic toughening mechanism gives rise to higher fracture energy than that pertinent to the matrix material. In principal the energy dissipated by this mechanism can be accounted for by a hybrid traction law, as in the current study, for the reinforced regions. However, it may be more suitable to introduce the fibre bridging mechanism within the reinforcement domain, by inserting cohesive surfaces between adjacent $0^{\circ}$ plies. If two adjacent plies are of differing orientations fibre bridging would not occur and therefore a cohesive surface would not be required. Within the matrix domain two sets of traction laws are required. These traction laws describe interlaminar failure and cracking in resin-rich regions, respectively. It will be necessary to introduce a characteristic length to determine which property is assigned to the matrix domain. For example, if cracking is to occur between adjacent reinforcement elements within a distance of one fibre diameter, approximately $7 \mu \mathrm{m}$, properties pertinent to the interlaminar failure mode should be used. Alternatively, if the crack is outside this characteristic distance the properties of the bulk epoxy will be used.

The promising result from the current work indicates that CDM or XFEM could be used to simulate damage in an embedded element model. Neither of these techniques not require apriori knowledge of the crack path, and would therefore be worthy of future research. A mesh independent solution combined with the embedded element technique will further reduce the time required to create and analyse a complex composite structure making this approach attractive for use in the preliminary and detailed design phases. 


\section{Conclusion}

A new approach to analyse interlaminar crack growth has been presented. In this method the embedded element technique is hybridised with a cohesive damage model to predict the onset and propagation of matrix cracking. A toughening mechanism was experimentally observed as the crack propagated through the resinrich region. Crack deflection was due to the mismatched stiffness at the bi-material interface and the higher strength of the bulk epoxy. It has been shown that with appropriate discretisation of the crack path the embedded element model predicted the failure phases, loads and crack growth observed experimentally. A coarse mesh approach was proposed where matrix cracking was constrained to occur between plies or along the bi-material interface. The coarse model was able to provide a good prediction of the experimentally observed fracture loads and crack length. Therefore the embedded element technique coupled with cohesive elements can accurately predict the evolution of delamination cracks in fibre reinforced composite structures containing resin-rich features pertinent to ply-drops. This new analysis approach can be used to efficiently analyse crack propagation in complex composite structures.

\section{Acknowledgements}

This research was conducted as part of a collaborative research program involving RMIT University, Deakin University, the University of Miami, Teledyne Scientific co. and industry partner Carbon Revolution. This research was supported under Australian 
Research Council's Linkage Projects funding scheme (project LP120200046). Financial support from the ARC and Carbon Revolution is gratefully acknowledged. The authors would like to acknowledge the support of R. Ryan and P. Tkatchyk (RMIT) for their technical assistance with sample preparation and mechanical testing. M.Y. Pitanga's (UNISAL) assistance with measuring the influence of fibre bridging is gratefully acknowledged. The authors would like to thank Dr B. Cox (Teledyne), Dr Q. Yang (University of Miami), Dr B. Trippit (Simuserv), Dr A. Denmead (Carbon Revolution) and Dr M. Silcock (Carbon Revolution) for technical discussions. The support of The RMIT Microscopy and Microanalysis Facility (RMMF) is kindly acknowledged. 


\section{References}

1. Federal Aviation Regulation (FAR) Part 23, Section 573-Damage tolerance and fatigue evaluation of structure, Federal Aviation Administration. 2005.

2. Advisory Circular (AC) 20-107B - Composite Aircraft Structure, Federal Aviation Administration. 2009.

3. Donatellis, M., Pirelli Formula 1 tyre modeling application with Abaqus, in 2013 SIMULIA Community Conference. 2013: Vienna, Austria.

4. Garg, A. and A. Abolmaali, Finite-Element Modeling and Analysis of Reinforced Concrete Box Culverts. Journal of Transportation Engineering, 2009. 135(3): $p$, 121-128.

5. Joosten, M.W., et al., Application of the Embedded Element Technique to Predict Interlaminar Failure, in American Society for Composites 29th Technical Conference, 16th US-Japan Conference on Composite Materials, ASTM-D30 Meeting. 2014: Price Center, University of California San Diego, La Jolla, CA USA.

6. Joosten, M.W., et al., Modelling Onset of Failure in Composite Structures Using the Enhanced Embedded Element Technique, in 8th Australasian Congress on Applied Mechanics (ACAM 8). 2014: Melbourne Convention Centre, Melbourne, Australia.

7. Tabatabaei, S.A., S.V. Lomov, and I. Verpoest, Assessment of embedded element technique in meso-FE modelling of fibre reinforced composites. Composite Structures, 2014. 107(0): p. 436-446.

8. Jiang, W.G., S.R. Hallett, and M.R. Wisnom, Development of domain superposition technique for the modelling of woven fabric composites, in Mechanical response of composites, Springer, Editor. 2008. p. 281-291.

9. Yang, Q.D. and B. Cox, Predicting failure in textile composites using the Binary Model with gauge-averaging. Engineering Fracture Mechanics, 2010. 77(16): $p$. 3174-3189.

10. Yang, Q.D. and B.N. Cox, Spatially averaged local strains in textile composites via the Binary Model formulation. Journal of Engineering Materials and Technology, 2003. 125: p. 418-425.

11. Fish, J., The s-version of the finite element method. Computers \& Structures, 1992. 43(3): p. 539-547.

12. Fish, J., et al., On adaptive multilevel superposition of finite element meshes for linear elastostatics. Applied Numerical Mathematics, 1994. 14(1-3): p. 135-164.

13. Tabatabaei, S.A. and S.V. Lomov, Eliminating the volume redundancy of embedded elements and yarn interpenetrations in meso-finite element modelling of textile composites. Computers \& Structures, 2015. 152(0): p. 142154.

14. Flores, S., et al., Treating matrix nonlinearity in the binary model formulation for 3D ceramic composite structures. Composites Part A: Applied Science and Manufacturing, 2010. 41(2): p. 222-229.

15. Gigliotti, L. and S.T. Pinho, Multiple length/time-scale simulation of localized damage in composite structures using a Mesh Superposition Technique. Composite Structures, 2015. 121: p. 395-405. 
16. Greco, F., et al., Crack propagation analysis in composite materials by using moving mesh and multiscale techniques. Computers \& Structures, 2015. 153(0): p. 201-216.

17. Allix, O., et al., Delamination prediction by continuum damage mechanics.In: Proceedings of the ,. : , 1997., in IUTAM Symposium - Variations of Domains and Free-boundary problems. 1997, Kluwer Academic Publishers: Paris, France. p. 163-171.

18. Ashari, S.E. and S. Mohammadi, Modeling delamination in composite laminates using XFEM by new orthotropic enrichment functions. IOP Conference Series: Materials Science and Engineering, 2010. 10(1): p. 012240.

19. Tsai, S., Mechanics of composite Materials. Part II - theoretical aspects. 1966: Wright-Patterson Air Force Base, Ohio.

20. ASTM, ASTM D5528-13, Standard Test Method for Mode I Interlaminar Fracture Toughness of Unidirectional Fiber-Reinforced Polymer Matrix Composites. 2013: West Conshohocken, PA.

21. ABAQUS, 'ABAQUS Documentation', Dassault Systèmes, Providence, RI, USA. 2014.

22. Wang, C.H., Fracture of interface cracks under combined loading. Engineering Fracture Mechanics, 1997. 56(1): p. 77-86.

23. Camanho, P.P., C.G. Davila, and M.F. de Moura, Numerical Simulation of MixedMode Progressive Delamination in Composite Materials. Journal of Composite Materials, 2003. 37(16): p. 1415-1438.

24. Goh, J.Y., et al., Effects of bondline flaws on the damage tolerance of composite scarf joints. Composites Part A: Applied Science and Manufacturing, 2013. 55(0): p. 110-119.

25. Sorensen, L., et al., Bridging tractions in mode I delamination: Measurements and simulations. Composites Science and Technology, 2008. 68(12): p. 23502358.

26. Airoldi, A. and C.G. Dávila, Identification of material parameters for modelling delamination in the presence of fibre bridging. Composite Structures, 2012. 94(11): p. 3240-3249.

27. Turon, A., C.G. Dávila, and P.P. Camanho, An engineering solution for mesh size effects in the simulation of delamination using cohesive zone models. Engineering Fracture Mechanics, 2007. 74(10): p. 1665-1682. 


\section{Figure Captions}

Figure 1: Schematic representation of (a) composite structure, (b) the host domain and (c) the embedded domain. Enhanced embedded element approach to simulate interlaminar matrix cracking (d) the host domain and (e) the embedded domain.

Figure 2: Schematic representation of the traction separation behaviour of a cohesive element. Figure 3: Possible cohesive failure locations in an embedded element model.

Figure 4: Detail view of the resin-rich region created by the discontinuous plies (left) schematic representation (right) as manufactured sample.

Figure 5: Schematic of the DCB ply-drop specimen.

Figure 6: Typical load-displacement curve for a DCB specimen containing a resin-rich feature.

NOTE: The square markers indicate when the crack position was measured.

Figure 7: Optical micrograph of the ply-drop region, side view (16X magnification). Crack growth occurred from left to right.

Figure 8: SEM image of the fracture surface and schematic representation of the crack path (bottom).

Figure 9: Mode I interlaminar fracture toughness as a function of opening displacement. Figure 10: Mode I interlaminar stress as a function of opening displacement (matrix cohesive response).

Figure 11: Schematic illustration of the crack tip as it enters the resin-rich region.

Figure 12: Normal and shear stresses near the crack tip, plotted as a function of $\theta$. Distance $=0.0021 \mathrm{~mm}$, Applied load $=50 \mathrm{~N}$.

Figure 13: Detail of FE meshes used to investigate matrix cracking (a) global geometry (a) coarse mesh $90^{\circ} \mathrm{crack}$ deflection (c) fine mesh with $90^{\circ}$ crack deflection (d) fine mesh with $32^{\circ}$ crack deflection $(\mathrm{e}, \mathrm{f}, \mathrm{g})$ embedded domain.

Figure 14: Comparison of experimental and predicted load-displacement response.

Figure 15: Predicted crack evolution for a deflection angle of $90^{\circ}$ (left column) host domain (right column) embedded domain. The arrows indicate the position of the cohesive zone.

Figure 16: Predicted crack evolution for a deflection angle of $32^{\circ}$ (left column) host domain (right column) embedded domain. The arrows indicate the position of the cohesive zone.

Figure 17: Comparison of experimental and predicated crack growth. 


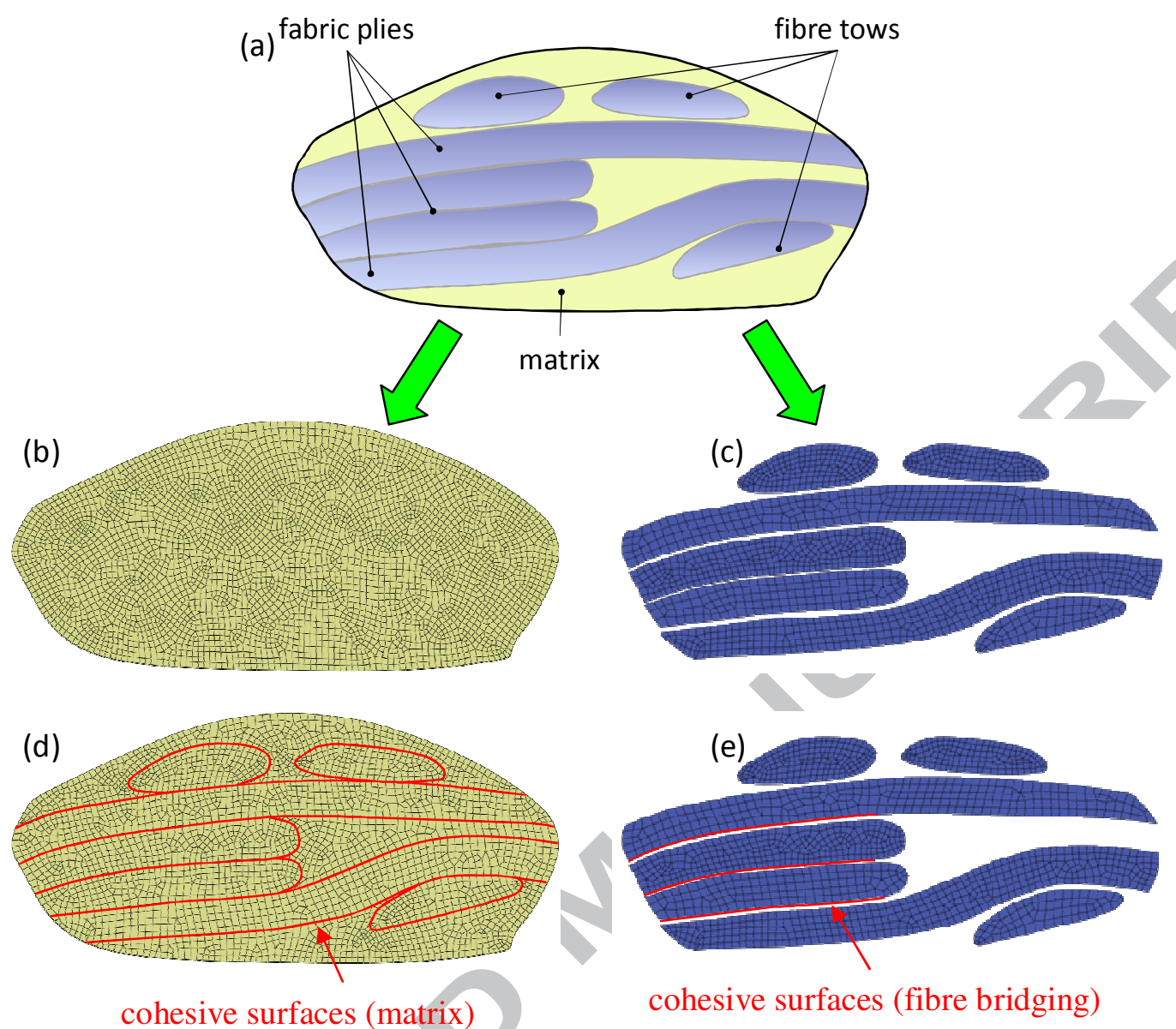

Figure 1: Schematic representation of (a) composite structure, (b) the host domain and (c) the embedded domain. Enhanced embedded element approach to simulate interlaminar matrix cracking (d) the host domain and (e) the embedded domain.

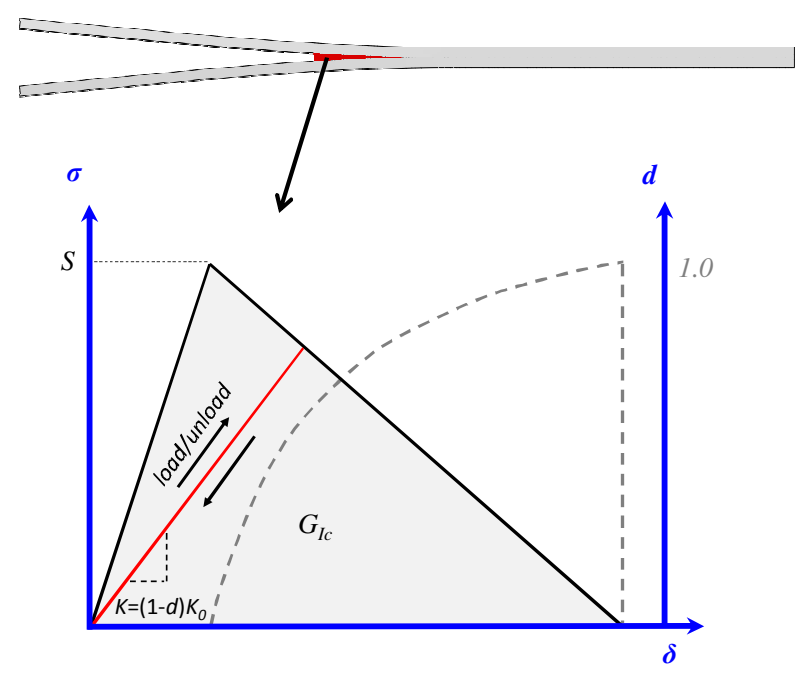

Figure 2: Schematic representation of the traction separation behaviour of a cohesive element 


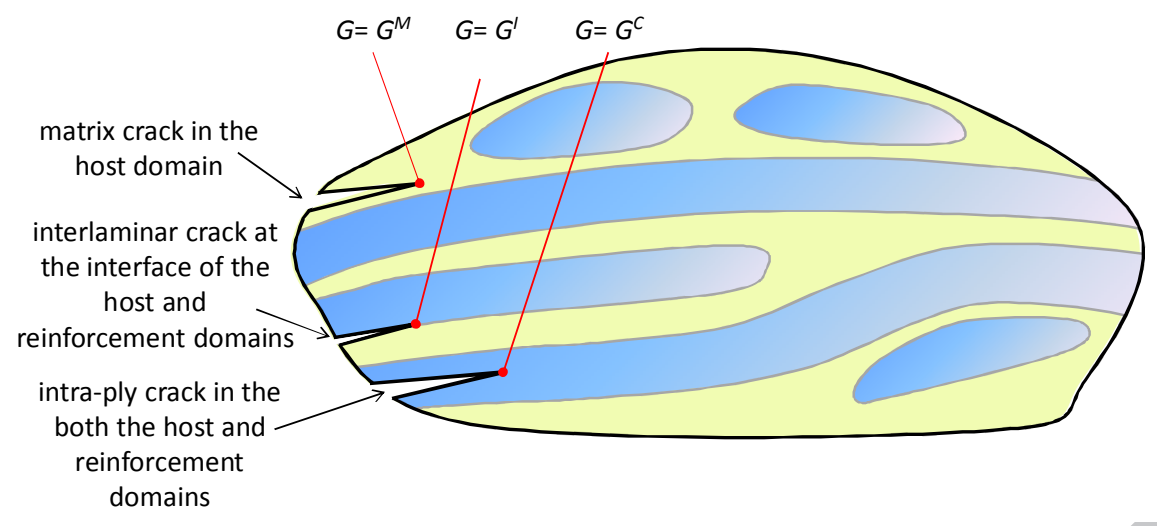

Figure 3: Possible cohesive failure locations in an embedded element model. 

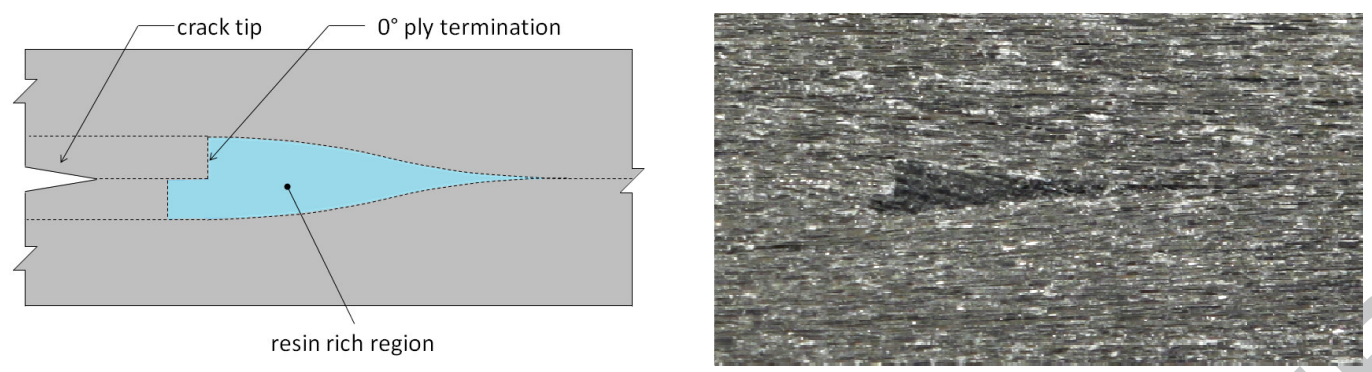

Figure 4: Detail view of the resin-rich region created by the discontinuous plies (left) schematic representation (right) as manufactured sample

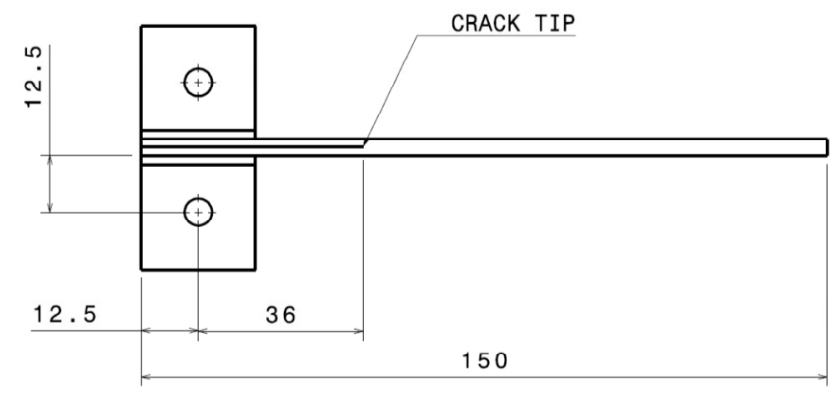

Figure 5: Schematic of the DCB ply-drop specimen

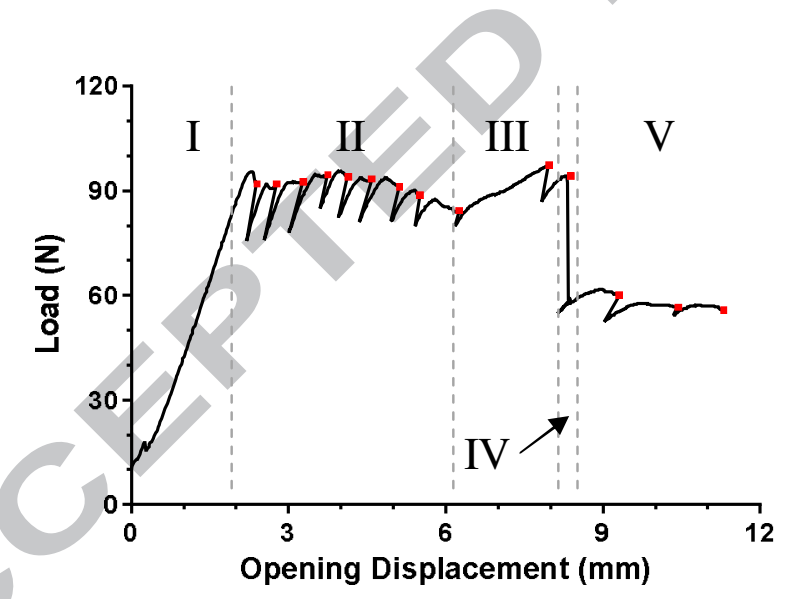

Figure 6: Typical load-displacement curve for a DCB specimen containing a resin-rich feature. 


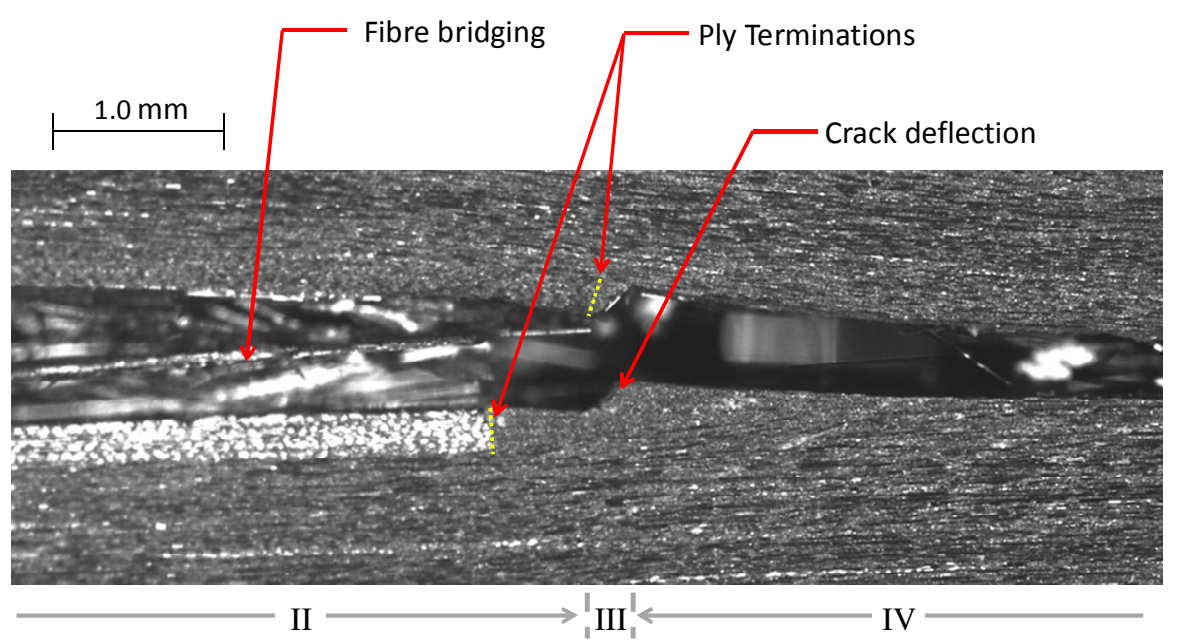

Figure 7: Optical micrograph of the ply-drop region, side view (16X magnification). Crack growth occurred from left to right.
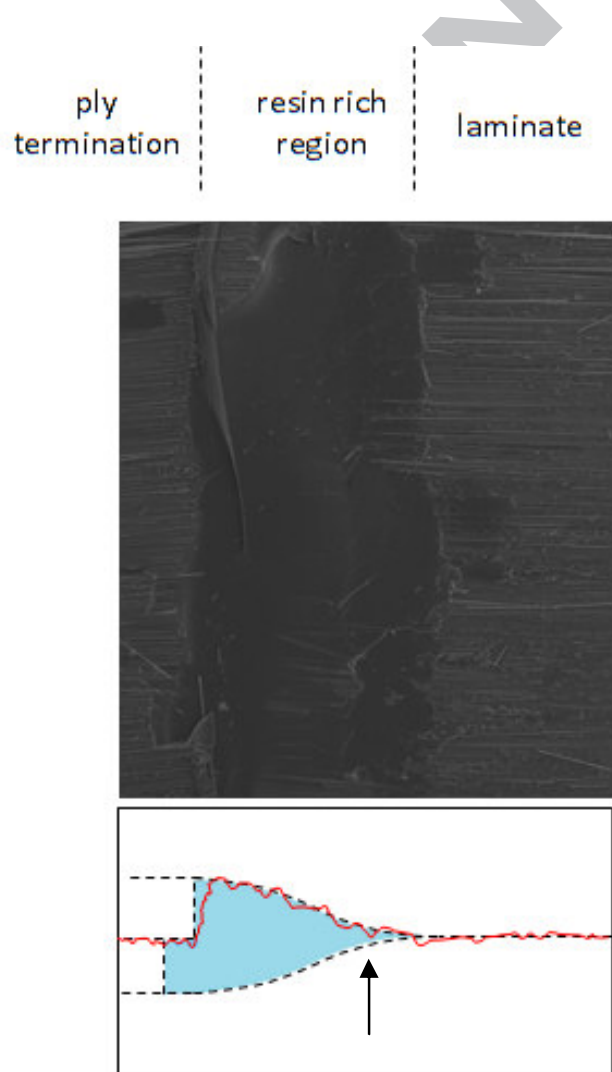

Figure 8: SEM image of the fracture surface and schematic representation of the crack path (bottom). 


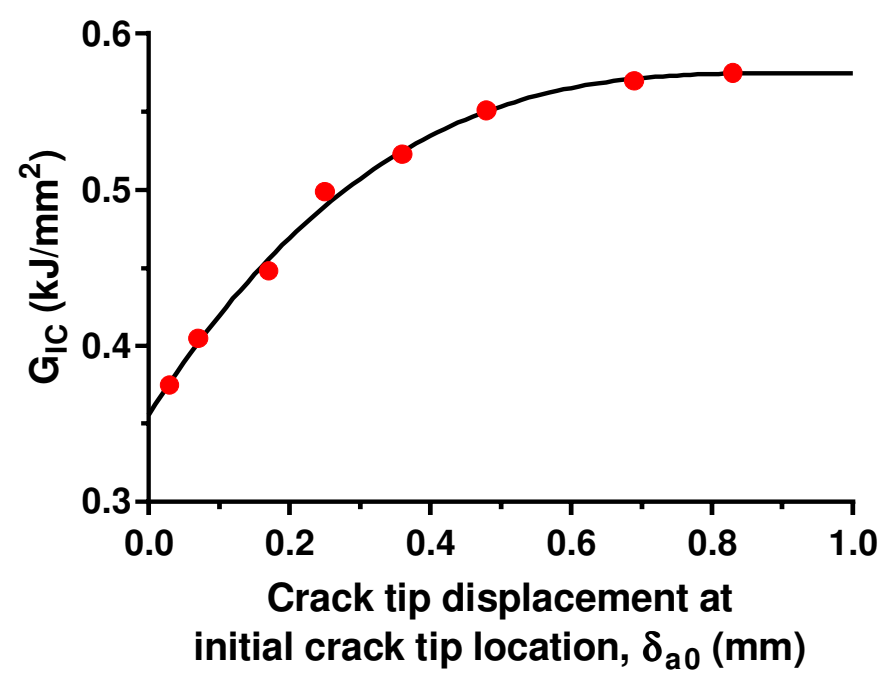

Figure 9: Mode I interlaminar fracture toughness as a function of opening displacement

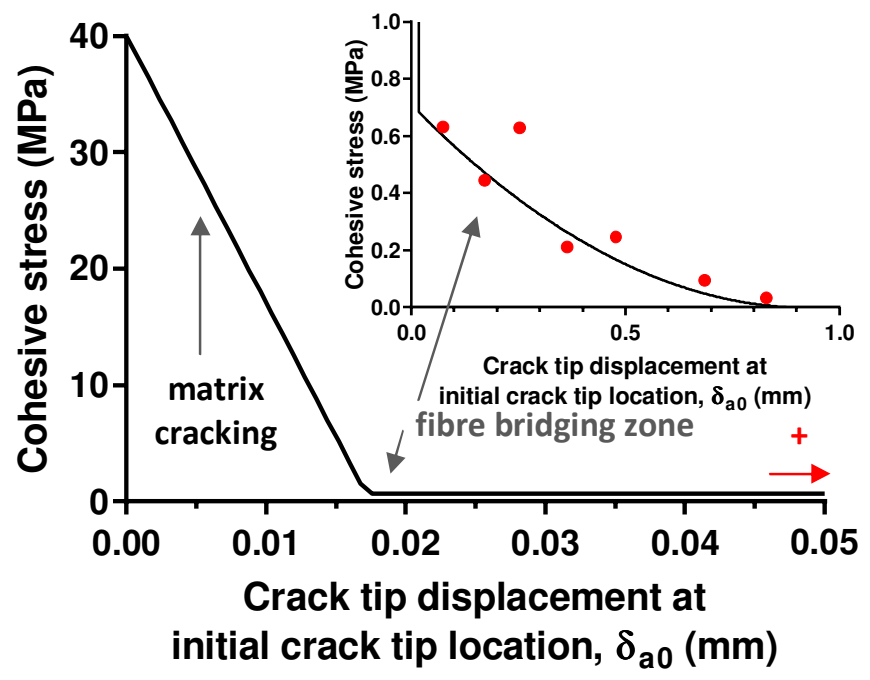

Figure 10: Mode I interlaminar stress as a function of opening displacement (matrix cohesive response) 


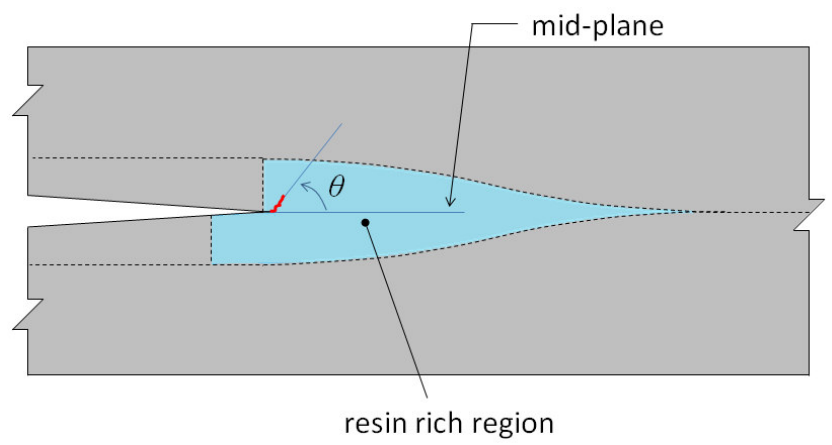

Figure 11: Schematic illustration of the crack tip as it enters the resin-rich region

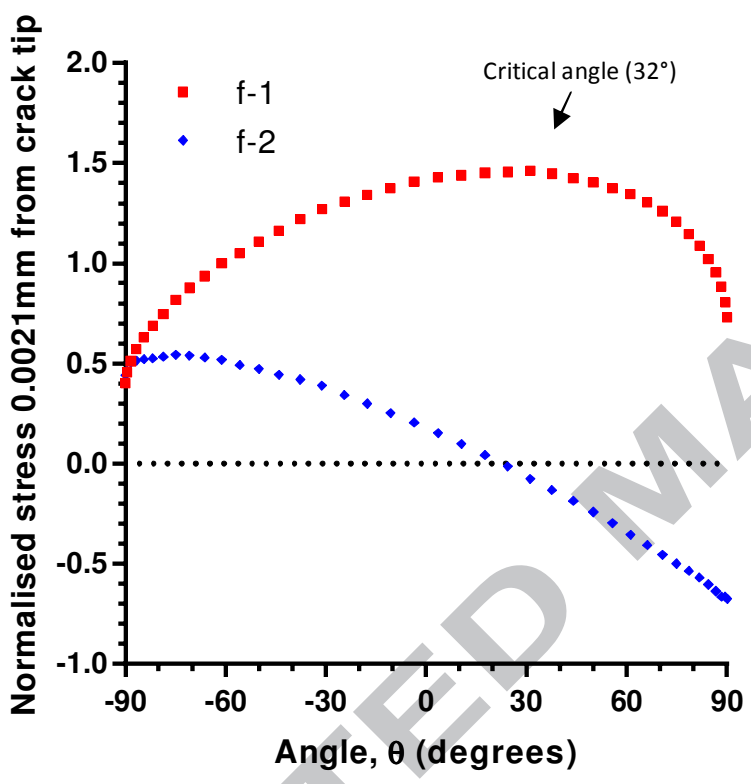

Figure 12: Normal and shear stresses near the crack tip, plotted as a function of $\theta$. Distance $=0.0021 \mathrm{~mm}$, Applied load $=50 \mathrm{~N}$ 
(a)
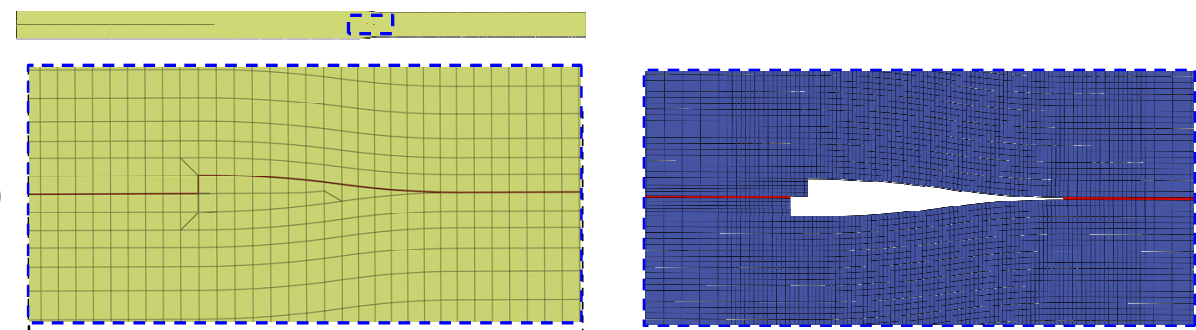

(e)

(c)
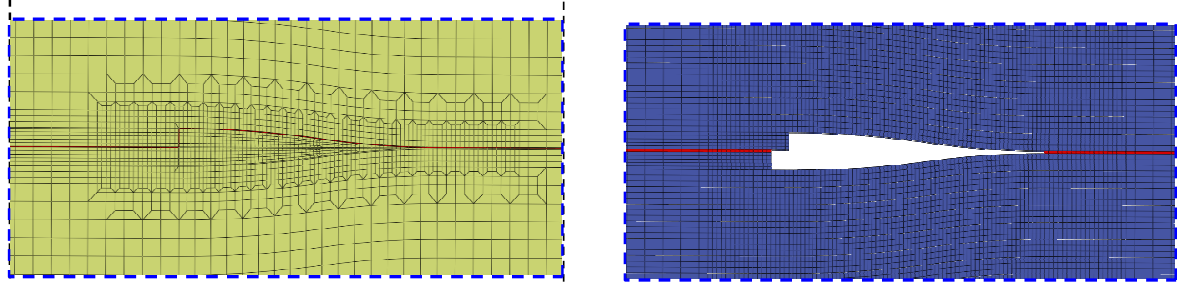

(f)

(d)
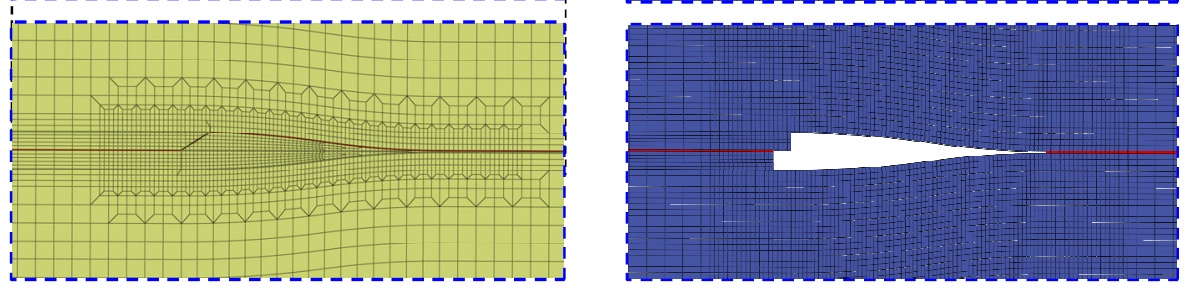

(g)

Figure 13: Detail of FE meshes used to investigate matrix cracking (a) global geometry (a) coarse mesh $90^{\circ} \mathrm{crack}$ deflection (c) fine mesh with $90^{\circ}$ crack deflection (d) fine mesh with $32^{\circ}$ crack deflection $(e, f, g)$ embedded domain.

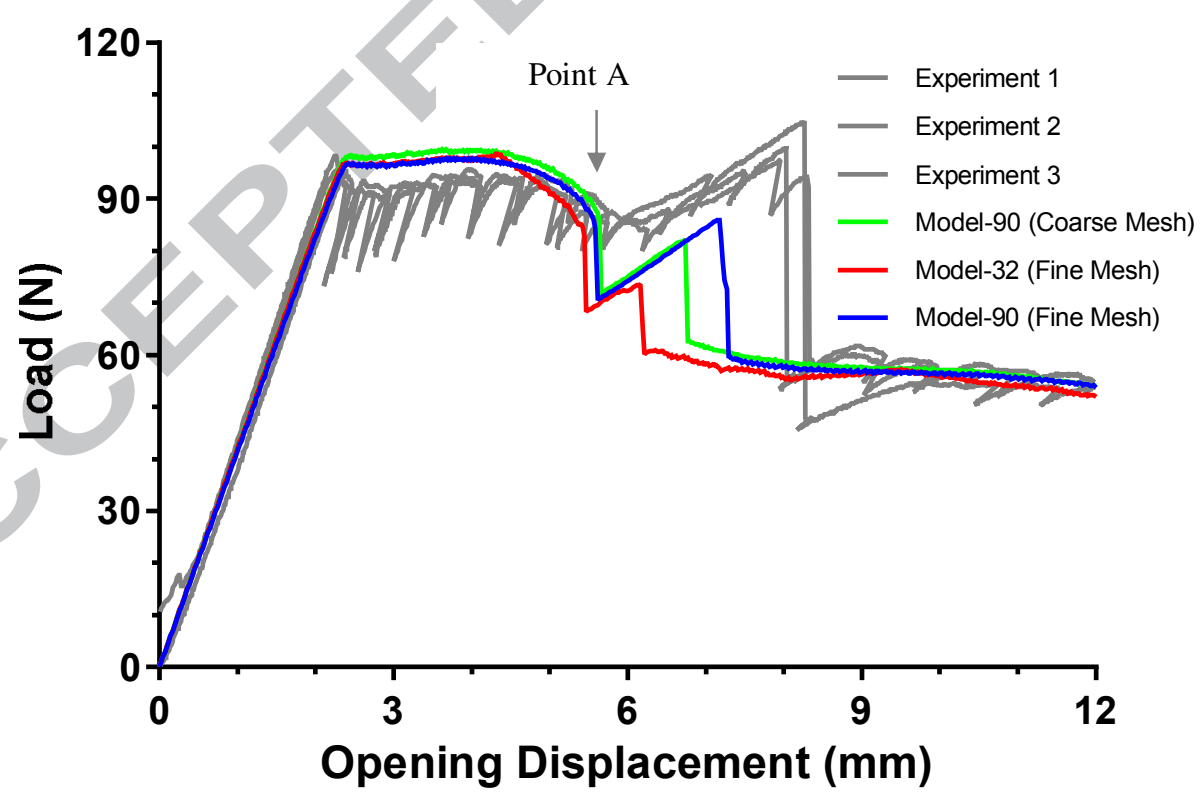

Figure 14: Comparison of experimental and predicted load-displacement response 

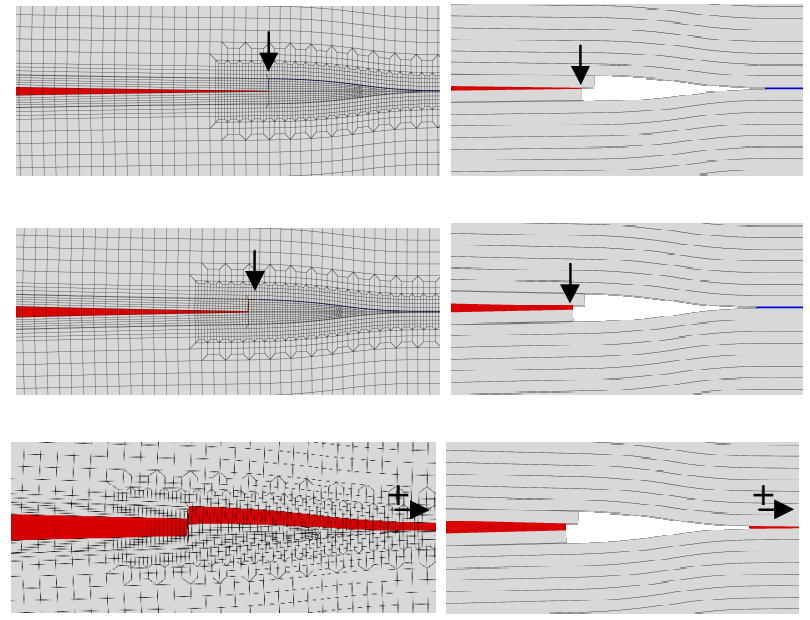

Figure 15: Predicted crack evolution for a deflection angle of $90^{\circ}$ (left column) host domain (right column) embedded domain. The arrows indicate the position of the cohesive zone.
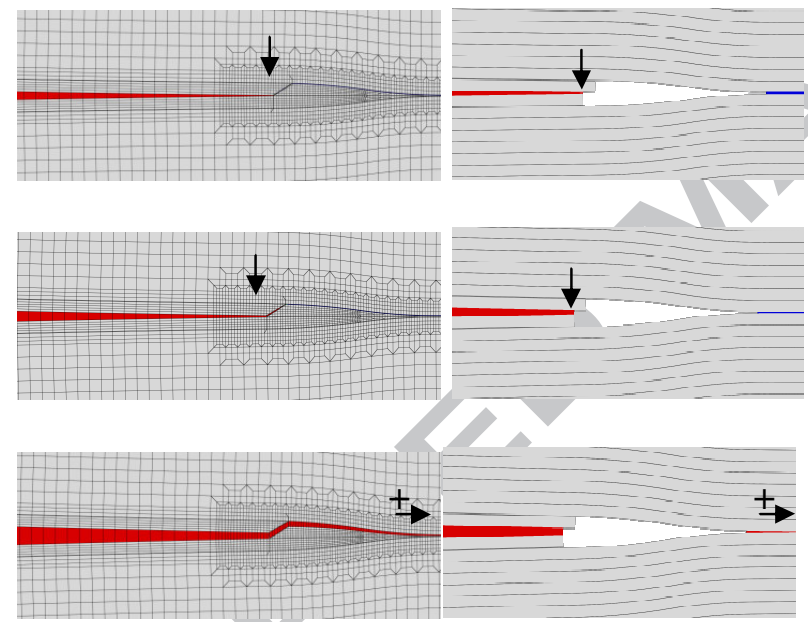

Figure 16: Predicted crack evolution for a deflection angle of $32^{\circ}$ (left column) host domain (right column) embedded domain. The arrows indicate the position of the cohesive zone. 


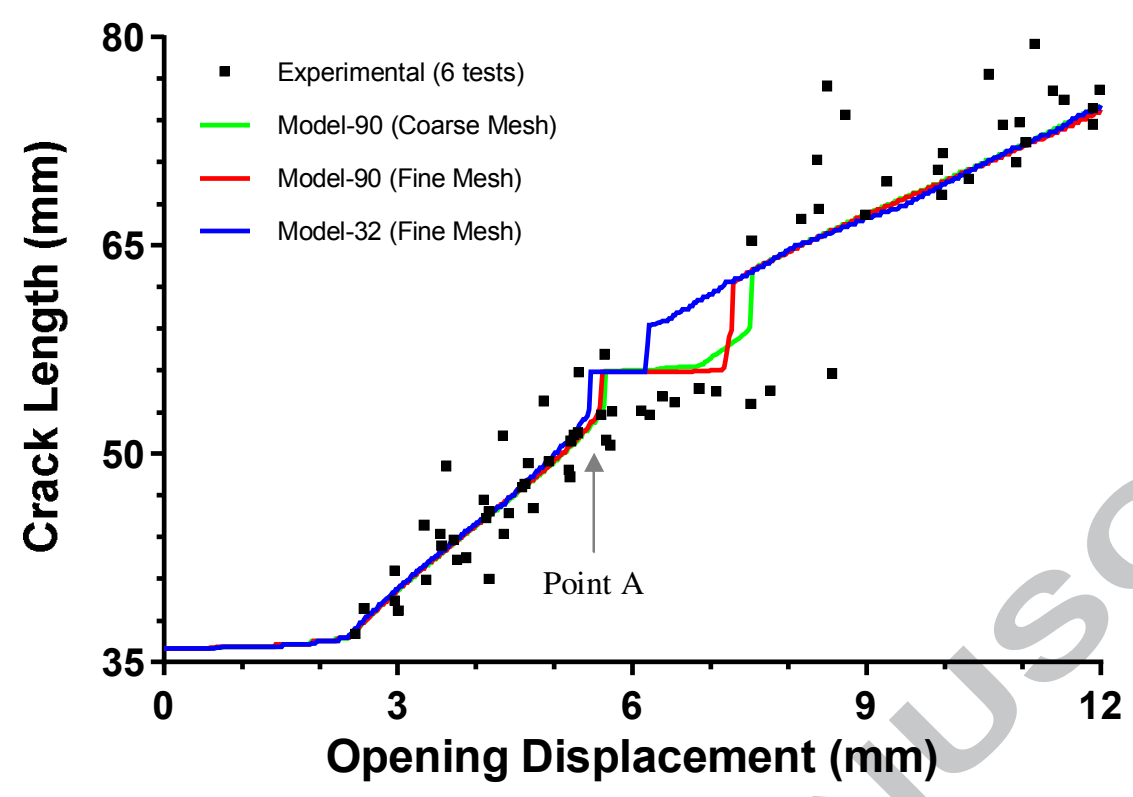

Figure 17: Comparison of experimental and predicated crack growth 


\section{Tables}

Table 1: Summary of ply material properties (T700/VTM264). [24]

\begin{tabular}{|c|c|c|}
\hline Symbol & Value & Units \\
\hline$E_{11}^{C}$ & 120,000 & $M P a$ \\
\hline$E_{22}^{C}$ & 7,500 & $M P a$ \\
\hline$E_{33}^{C}$ & 7,500 & $M P a$ \\
\hline$v_{12}^{C}$ & 0.32 & - \\
\hline$v_{13}^{C}$ & 0.32 & - \\
\hline$v_{23}^{C}$ & 0.33 & - \\
\hline$G_{12}^{C}$ & 3,900 & $M P a$ \\
\hline$G_{13}^{C}$ & 3,900 & $M P a$ \\
\hline$G_{23}^{C}$ & 2,820 & $M P a$ \\
\hline
\end{tabular}

Table 2: Summary of material properties of the matrix domain (VTM264 resin).

\begin{tabular}{|c|c|c|}
\hline Symbol & Value & Units \\
\hline$E$ & 3,800 & $\mathrm{MPa}$ \\
\hline$v$ & 0.33 & - \\
\hline$\sigma$ & 80 & $\mathrm{MPa}$ \\
\hline
\end{tabular}

Table 3: Summary of material properties assigned to the reinforcement domain.

\begin{tabular}{|c|c|c|}
\hline Symbol & Value & Units \\
\hline$E_{11}^{R}$ & 116,194 & $\mathrm{MPa}$ \\
\hline$E_{22}^{R}$ & 2,884 & $\mathrm{MPa}$ \\
\hline$E_{33}^{R}$ & 2,884 & $\mathrm{MPa}$ \\
\hline$v_{12}^{R}$ & 0.292 & - \\
\hline$v_{13}^{R}$ & 0.292 & - \\
\hline$v_{23}^{R}$ & 0.036 & - \\
\hline$G_{12}^{R}$ & 2,471 & $\mathrm{MPa}$ \\
\hline$G_{13}^{R}$ & 2,471 & $\mathrm{MPa}$ \\
\hline$G_{23}^{R}$ & 1,391 & $\mathrm{MPa}$ \\
\hline
\end{tabular}


Table 4. VTM264 resin cohesive material properties

\begin{tabular}{|c|c|c|c|}
\hline Symbol & $\begin{array}{c}\text { Value } \\
\text { (coarse } \\
\text { model) }\end{array}$ & $\begin{array}{c}\text { Value } \\
\text { (fine } \\
\text { model) }\end{array}$ & Units \\
\hline $\mathrm{L}$ & 0.01 & 0.01 & $\mathrm{~mm}$ \\
\hline$E$ & 7,500 & 7,500 & $\mathrm{MPa}$ \\
\hline$G$ & 3,800 & 3,800 & $\mathrm{MPa}$ \\
\hline$S$ & 46 & 80 & $\mathrm{MPa}$ \\
\hline$K$ & 0.35 & 0.35 & $\mathrm{~kJ} / \mathrm{mm} 2$ \\
\hline$\alpha$ & 1.78 & 1.78 & - \\
\hline
\end{tabular}

Table 5. T700/VTM264 interlaminar cohesive material properties [24]

\begin{tabular}{|c|c|c|}
\hline Symbol & Value & Units \\
\hline$L$ & 0.01 & $\mathrm{~mm}$ \\
\hline$E_{33}^{C}$ & 7,500 & $\mathrm{MPa}$ \\
\hline$E_{13}^{C}=E_{23}^{C}$ & 3,800 & $\mathrm{MPa}$ \\
\hline$S_{33}$ & 40 & $\mathrm{MPa}$ \\
\hline$S_{13}=S_{23}$ & 78 & $\mathrm{MPa}$ \\
\hline$G_{I C}^{i}$ & 0.35 & $\mathrm{~kJ} / \mathrm{mm}^{2}$ \\
\hline$G_{I I C}^{i}=G_{I I I C}^{i}$ & 1.62 & $\mathrm{~kJ} / \mathrm{mm}^{2}$ \\
\hline$\alpha$ & 1.78 & - \\
\hline
\end{tabular}

